\title{
The Effects of Mongolian Tourism Service Qualities on Foreign Visitors' Satisfaction and Re-visit Intention: Moderating Effect of Destination Image
}

\author{
Yanjinlkham Khurelchuluun, Ph.D. student, Business Administration, Kumoh National Institute of \\ Technology, 61, Daehak-ro, Gumi-si, Gyeongsangbuk-do, 39177, Republic of Korea, yanjkakh@gmail.com \\ *Gwi-Gon Kim, Professor, Business Administration, Kumoh National Institute of Technology, 61, Daehak-ro, \\ Gumi-si, Gyeongsangbuk-do, 39177, Republic of Korea, metheuskim@daum.net \\ *Corresponding Author
}

\begin{abstract}
This study is to examine the Mongolian tourism service qualities influence on foreign visitors' satisfaction and the re-visit intention. This study also confirmed the moderating effect of destination image. We gathered surveys from 230 international tourists at the largest tourist attraction "Chinggis Khaan Statue complex" and "Tumen Ikh Ensemble" in Ulaanbaatar city, Mongolia. In order to test the hypothesis, the relationship between tourism service quality and visitors' satisfaction was verified by multiple regression analysis. Moderating effect of destination image between tourism service quality and visitors' satisfaction was verified by moderation regression analysis.

The results of this study as follows: 1) Monetary advantages and convenience advantages of the tourism service qualities had a positive impact on foreign visitors' satisfaction. In contrast, safety and security had a negative impact on visitors' satisfaction. 2) The effect of convenience on visitors' satisfaction was moderated differently by the levels of natural image and cultural image (high vs. low). 3) The higher visitors' satisfaction was the higher re-visit intention got. The findings of this research help us to examine the effects regarding tourism service quality of Mongolia. That is, the findings can contribute to establishing marketing strategies to improve satisfaction of tourists, and, ultimately, raise revisit intention of them to Mongolia through providing services suitable to the image of Mongolian tourism.

As a final point, since there are more factors in the quality of tourism services, it is a great need to study other tourism service quality.
\end{abstract}

Keywords: Monetary Advantages, Safety and Security, Convenience Advantages, Destination image, Visitors' Satisfaction, Re-visit intention

$\begin{array}{lll}\text { Received: 08.12.2020 } & \text { Accepted: 11.01.2021 } & \text { Published: 07.02.2021 }\end{array}$

\section{INTRODUCTION}

Tourists have continuously grown across the world. In 2018, the number of tourists in the world reached about 1.4 billion, 6\% increase from 1.322 billion in the previous year [1]. Tourism is on e of major industries in the world, contributing greatly to national economies. With economic de velopment, various kinds of tourism service have become available, and ubiquitous platforms areu sed as tools of the tourism industry. In particular, tourism is treated as an essential element in economic development policies.

Mongolia is one of a few countries, which still preserve nomadic culture and natural resources. Emerging as an attractive tourism destination, Mongolia attracts numerous tourists from the world. In Mongolia, tourism- related service business started in 1954. In addition, with the change of the regime into a democracy in 1990, tourism business has greatly grown. Mongolia has a deep history extending to Asia and Europe. In the 13th century, Chinggis Khaan expanded its territory to about 1/3 of the world. Mongolia has an image of wide steppe and desert, various wild flowers and blue lakes, etc. According to the Tourism Law of Mongolia, tourist sites maintain resources like proper nature, history, and culture. The country classifies tourism sites into six regions: the Khuvsgul region preserving natural beauty, the Orkhon region containing cultural relics, Gobi Desert containing unique and mysterious nature, the Khentii region which begins the history of Chinggis Khan, the Altain region where customs and cultures of different tribes exist, and, finally, the Ulaanbaatar around [2].

Tourists have increased every year to enjoy Mongolia-specific tastes. In 2019, 577,300 tourists came to the country. The majority of them (69.7\%) visit the country from April to September [3]. As the reasons for visiting Mongolia, the largest proportion of tourists (36\%) designates enjoying wild animals and 
nature tourism, followed by experiencing nomadic life and customs (28\%), visiting historic relics (14\%), experiencing adventure (8\%), and others (14\%). Expanding tourism business contributes greatly to Mongol economy [4].

Tourism agencies, tourism companies, accommodations (hotel, ger camp, etc.), transportation, tour guide service, traditional food restaurants, and traditional facilities are being built and prepared. According to the report of national competitiveness of the World Economic Forum (WEF), Mongolia is ranked the 93rd in the world, and the 16th in Asia. So, the quality of tourism competitiveness of Mongolia is not high [5]. It is the reason why the necessity of strengthening tourism service quality to satisfy needs of tourists is a national issue in the country.

This paper aimed to develop effective marketing strategies in Mongol tourism business. To fulfill the research aim, this research analyzed tourists' satisfaction with tourism sites, facilities, service quality, and prices. That is, this research wanted to identify whether foreign tourists actually experienced what they expected before coming to Mongolia, how much they were satisfied, and whether they wanted to visit the country again.

\section{Literature review and hypotheses}

\section{Tourism service quality on visitors' satisfaction}

Service is activities or benefits provided simultaneously with the sale of products. Service quality is the degree to which it is perceived by subjectivity of individual, and, it is continuous evaluation of a certain object, and is different from satisfaction [6]. There is few tangible clues to measure service quality. In most cases, tangible clues are limited to personal elements and physical ability of service provider. It is caused by unique characteristics of service - intangibility, simultaneity, heterogeneity, and extinction. Specifically, intangibility is the essential element differentiating product and service. Unlike product, service cannot be suggested as objective form to anybody, and it cannot be touched and seen. Simultaneity is the process in which production and consumption are made at the same time. Customer always exists at the time when service is provided. Simultaneity of service forms close relationship between production process and customer. Heterogeneity means changeable elements between service production and delivery process. The service received by customers can be different. Extinction means that service cannot be stored. Quality related with such service characteristics is the scale how a certain product or service fits the standards.

Tourism service quality is an important element to attract tourists and activate their willingness to visit again. Improvement of tourism service quality can serve to satisfaction of customers, improvement of productivity, reduction of cost, and improvement of positive image of destination [7]. Tourism service quality is evaluated from the stage where tourists collect information and make plans for coming travel. Consumers determine qualities at every moment when they use airplane, and other vehicles, lodges, food, accommodations, and tour plans. There is no perfect and universalized definition of tourism service quality. The quality is judged by subjective thinking of tourists. Satisfaction of tourist is the result of comparing he or she expected and what he or she really experienced at the site [8]. The demand or expectation the tourist had before visiting the site is an important criterion to judge the service quality he or she experiences at the site. If tourists favorably evaluate the service quality of a specific tourist site, the site will attract more visitors.

In contrast, if the level of service quality visitors perceive is low, the number of visitors will decrease. By improving service quality, one can improve customer satisfaction, productivity, reduce cost, and strengthen positive image of the site, service quality including service, facilities, and information provided by Purnululu National Park in Australia has positive effect on customer satisfaction [9]. Plus, satisfaction of tourists is also affected by service provider and interaction with other tourists. In short, monetary advantages, convenience, safety, and security end up as important elements of tourism service quality [10].

This research examined the effects of tourism service quality of tour to Mongolia such as monetary advantages, safety and security, and convenience on the foreign tourists' satisfaction. First, monetary advantage is very important in choosing destinations. Flexible price setting and wide differentiation of prices for the same service impose different prices to different customers [11]. As tourism service, prices are low in price transparency, fairness of prices is not guaranteed compared with prices of common products. As tourists make tour plans for a long time, and want to save prices. Thus, it is possible that they want to intervene in choice of tour service. Compensation or benefits to the price tourist pays determine satisfaction of the tourist. In short, as service charge affects tourist satisfaction [12], this research set H1.

H1: Monetary advantages will have positive impact on visitors' satisfaction. 
Safety and security are essential elements of tour quality. All the organizations and groups related with tourism (transportation service, government, tourist companies, non-profit organizations, media, and citizen groups, etc.) should cooperate to provide tourists with safety and security [13]. Tourist safety is threatened by car accident, anxiety about public transportation, anxiety about security of food and lodges, and safety of tourist attractions. Tourists visiting a new place get information about it about positive and negative aspects of it. By depending more on external information sources, tourists can get uncertainty and risks [14]. The problems related with tourism safety is a very sensitive issue affecting tourists. If tourists feel danger in a specific destination, they will have negative image toward the destination. It will not only harm the tourism business of the country, but cause reduction of tourists. Safety is a core issue in decision-making of tourists, and tourists tend to select the place which is low in danger and high in security [15]. Safety is the basic requirement in attracting foreign tourists, and essential social infrastructure to make tourists visit the site again. Thus, this research set $\mathrm{H} 2$.

H2: Safety and Security will have positive impact on visitors' satisfaction.

Service conveniences are time and effort customer can save while procuring and using service [16]. Service conveniences not only include fundamental demands of tourists such as lodging, shopping, and access, but additional conveniences like tourist information, festivals, experiencing products, money exchange and refund. As tourism service conveniences are core elements in using product or service, customers are very sensitive to them. Maximizing conveniences is to save cognitive, emotional and physical activities while purchasing and using service [17]. Assuming that the easier collection of information and using process of travel agencies, hotel, information center, and transportation are, they save time and effort of tourists, this research set H3.

H3: Convenience advantages will have positive impact on visitors' satisfaction.

\section{Moderating effect of destination image}

The image of a tourist destination is comprehensive perception of tourists about the destination such as culture, nature, and social characteristics of it [18]. Destination image is an important element affecting the decision of tourist to travel to it. The destination image includes affective element tourists get from the destination and cognitive element on personal beliefs and knowledge about it [19].

This research considered cognitive image. Cognitive elements are based on natural environment, cultural relics, tourism infrastructure and atmosphere. When we think of a tourist destination, we form an image about it based on cognitive elements. All the external stimuli of a tourist destination affect cognitive elements, and service quality and destination image, which come under external stimuli (cost, safety, and convenience, etc.), can interact one another. Cognitive elements of destination image are landscape \& surroundings, nature, culture, nightlife \& entertainment, attraction \& shopping facilities, and others [20].

Mongolian tour consists mainly of nature and culture. It is possible to form the image of Mongolian tourism as ecological tour and culture tour. Such an image of nature is very important in selecting tour destination.

Nature tour is to appreciate and enjoy unpolluted and natural wild plants, animals, and cultures in such environment [21]. To effectively enjoy nature, tourists can give up conveniences of parking, and accommodations. Therefore, the more a tourist attraction has the positive image of nature tourism, the more they get satisfaction. Mongolia has clear image of nature. Tourists to Mongolia may not expect good facilities. Mongolia has abundant World Cultural Heritages, beautiful natural resources, various cultural and historical properties. Considering that the 'beautiful nature and wild animals' (36\%) took the first place in the purpose of Mongolian tourism, it shows the high natural image of Mongolia. Thus, this research set $\mathrm{H} 4$.

H4. Natural image will moderate the relationship between convenience advantages and visitors' satisfaction.

Culture tour is based on cultural motivation, and consists of learning tour, performance art, festival and other cultural event tour, and visit to cultural and historic sites. Culture is tourist resources including all the attractive cultural heritages [22]. Culture tour is composed of history, culture, historic site and monument, place of historic accident, scenery, art (music or literature), festival, and traditional life style, etc.,[23]. It also includes museum, festival, architecture, relics, food, language, religion and historic sites. In a research, dealing with the relationship between culture tour experiences and satisfaction respondents answered that as they boost their knowledge on culture and history when they visit famous temples or museums, they are satisfied with the visit. Mongolia has a strong cultural image with relics from old history, nomadic life styles, Naadam festival and history of Genghis Khan. We can expect that the demands for convenience will not high for tourists of Mongolia with the strong natural image. Thus, this research set H5. 
H5. Cultural image will moderate the relationship between convenience advantages and visitors' satisfaction.

\section{Impact of visitors' satisfaction on the re-visit intention}

Re-visit intention is tourist's intention to revisit the same destination, or recommend it to others [24]. It has been known that the more satisfied the tourist is, the more he or she intends to visit again. Tourists satisfied with their tour of a certain place are likely to revisit it or recommend it to others. Other research found that good service quality of a destination has positive effect on satisfaction and revisit intention [25]. The more satisfied with tourism service, the higher revisit intention gets, and the potential tourists get, this research set $\mathrm{H} 6$.

H6: Visitors' satisfaction will have positive impact on re-visit intention

\section{Tourism service quality}

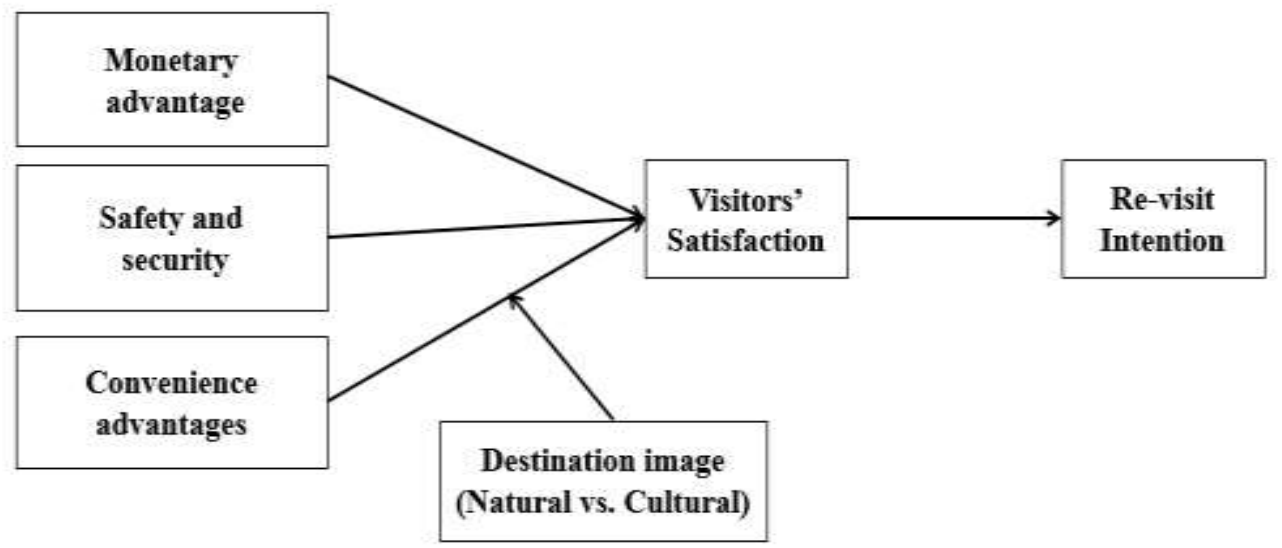

Figure 1. Research model

\section{Materials and methods}

\section{Sample design and data collection}

This research conducted a survey to tourists visiting famous tourist attractions, Chinggis Khaan Statue complex and Tumen Ikh Ensemble, 74km away from Ulan Bator, capital of Mongolia for about 2 months from February to April, 2019. The questionnaire was written in English, and respondents were selected with convenience sampling method. Each respondent was asked to fill out the questionnaire by oneself. The measurement items in each variable included in the questionnaire were the tourism service quality (monetary advantages, safety and security, and convenience advantages), destination image (natural vs. cultural), visitors satisfaction, revisit intention, demographic characteristics, and tour experiences. By providing each respondent with calligraphy of the respondent's name on Mongolian traditional paper, this research persuaded him or her to be sincere in filling out the questionnaire. Among 230 filled out copies of the questionnaire, this research finally used 204 copies for final analysis, excluding the copies insincerely filled out.

\section{Measurements}

Tourism service quality was measured with three attributes: monetary advantages was measured with 4 items of the scale of Han (2013) [26]; safety and security with 4 items of Richard George (2002) [27]; convenience advantages with 11 items selected from Kim, S. S., Lee, C. K., \& Klenosky, D. B. (2003) [28]. Respondents were asked to answer the statement by designating a point from 7-point Likert scale (from 1 $=$ Totally Disagree to 7=Fully Agree). Destination image was measured with 2 concepts: natural image was measured with 10 items chosen from those used by Malik, M. I., \& Bhat, M. S. (2015); Chen, \& Phou (2013) [29,30], cultural image with 7 items from Stojanovic, I., Andreu, L., \& Curras-Perez, R. (2018) [31]. Respondents were to point a point from the above-mentioned 7-point Likert scale.

The case of being high in natural image was Mean>6.09 (31.9\%) and the case of being low in natural image was Mean<5.02 (30.9\%). The case of being high in cultural image was Mean>5.57 (31.9\%), and the case of being low in cultural image was Mean<5.57 (39.2\%). To measure visitors' satisfaction, this 
research used 4 items used by Han (2013) [26]. To measure re-visit intention, this research used 3 items used by Tan \& Wu (2016) [32]. Respondents answer on the above mentioned 7-point Likert scale.

\section{Exploratory factor analysis and reliability}

The validity of the model can be identified with EFA (exploratory factor analysis), KMO (Kaiser-MeyerOlkin) test, and Bartlett test. First, factors combining variables matched the aims of this research and were well differentiated. All the factor loadings were $>0.588$. KMO test also showed that all values were $>0.744$, Bartlett's test of sphericity showed probability value $<.05$, proving that the model is suitable for factor analysis. In reliability test, Cronbach-alpha is $>0.78$, showing that it has internal consistency.

\section{Result of hypothesis testing and discussion}

This research used 3 kinds of tourism service quality attributes (monetary advantage, safety and security, and convenience advantage) as antecedents of service satisfaction. In addition, it examined moderating effects of destination images (natural and cultural). Finally, it examined the relationship between service satisfaction and revisit intention. $\mathrm{H} 1, \mathrm{H} 2, \mathrm{H} 3$ were to test the effects of variables on service satisfaction through multiple regression analysis. $\mathrm{H} 4$, $\mathrm{H} 5$ were to test moderating effects of destination images using moderation regression analysis. $\mathrm{H} 6$ was to examine relationship between service satisfactions and revisit intention through linear regression analysis.

\section{Results for $\mathrm{H} 1, \mathrm{H} 2$ and $\mathrm{H} 3$}

$\mathrm{H} 1$ on the relationship between Monetary advantages and visitors' satisfaction had B=.430, $\mathrm{p}<.05$. The slope was statistically significant. $\mathrm{H} 1$ was adopted. $\mathrm{H} 2$ on the relationship between safety and security and service satisfaction had $\mathrm{B}=-.029, \mathrm{p}>.05$. Thus, $\mathrm{H} 2$ was rejected. $\mathrm{H} 3$ on the relationship between convenience advantages and visitors' satisfaction had $B=.328, p<.05$. As it was statistically significant, $\mathrm{H} 3$ was supported [Table 1].

Table 1: The Relationship between Independent Variables and Dependent variable

\begin{tabular}{|l|l|l|l|l|}
\hline \multirow{2}{*}{ Independent Variables } & \multicolumn{2}{|l|}{ Unstandardized Coefficients } & \multirow{2}{*}{ T } & \multirow{2}{*}{$p$} \\
\cline { 2 - 4 } & $\mathrm{B}$ & $\mathrm{S} . \mathrm{D}$ & 6.9251 & .000 \\
\hline Monetary Advantages & .430 & .062 & -.532 & .595 \\
\hline Safety and Security & -.029 & .054 & 4.436 & .000 \\
\hline Convenience Advantages & .328 & .074 & & \\
\hline $\mathrm{R}^{2}=.532 \quad$ Adjusted $\mathrm{R}^{2}=.525$ & $\mathrm{~F}=75.810$ & &
\end{tabular}

\section{Results for $\mathrm{H} 4$ and $\mathrm{H} 5$}

H4 was on moderating effect of interaction of two groups on dependent variable. In the mode-2, the statistics were significant with $\mathrm{R}^{2}=.537$, Adjusted $\mathrm{R}^{2}=.530, \mathrm{~F}=3.496, \mathrm{p}<.1$. In addition, to judge final moderating effect, we need to test whether the interaction item is significant and whether the direction of interaction item is correct. The statistics of the item (Convenience advantages * Natural image) were $t=-$ 1.870, $\mathrm{p}=.063$, significant at significance level 0.1 Standardized coefficient was -.752. Consequently, convenience advantages and natural image have moderating effect [Table 2].

Table 2: Interaction effect of Convenience Advantages and Natural image

\begin{tabular}{|c|c|c|c|c|c|}
\hline \multirow{2}{*}{\multicolumn{2}{|c|}{ Variables }} & \multicolumn{2}{|c|}{ Unstandardized Coefficients } & \multirow{3}{*}{$\begin{array}{l}t \\
6.890\end{array}$} & \multirow{3}{*}{$\begin{array}{l}p \\
.000\end{array}$} \\
\hline & & \multirow{2}{*}{$\begin{array}{l}\mathrm{B} \\
.404\end{array}$} & \multirow{2}{*}{$\begin{array}{l}\text { S.D } \\
.059\end{array}$} & & \\
\hline \multirow[b]{2}{*}{1} & Convenience & & & & \\
\hline & Natural image & .431 & .063 & 6.866 & .000 \\
\hline \multirow[b]{2}{*}{2} & Convenience(Con) & .854 & .248 & 3.450 & .001 \\
\hline & Natural image(NI) & .836 & .225 & 3.711 & .000 \\
\hline
\end{tabular}




\begin{tabular}{|l|l|l|l|l|l|}
\hline & Con* NI & -.080 & .043 & -1.870 & .063 \\
\hline $\mathrm{R}^{2}=.537 \quad$ Adjusted $\mathrm{R}^{2}=.530$ & $\mathrm{~F}=3.496$ & & \\
\hline
\end{tabular}

The effect of convenience on service satisfaction depending on the level of natural image (high vs. low). To analyze the relationship, this research divided respondents into two groups (those with high natural image and those with low natural image) and did regression analysis between convenience and visitors' satisfaction for two groups. The analysis showed that for those who have high natural image, the statistics were $\mathrm{B}=-.014, \mathrm{t}=-.144, \mathrm{R}^{2}=.321, \mathrm{~F}=11.166, \mathrm{p}>.05$. For those who have low natural image, the statistics were $B=.351, t=2.902, R^{2}=.683, F=32.300, p<.05$. Therefore, When the Mongolian natural image was high convenience advantages did not have significant effect on visitor's satisfaction. However, when the natural image was low, convenience advantages had positive effect on visitors' satisfaction [Table3].

Table 3: Visitors' satisfaction depending on level of natural image (high vs. low)

\begin{tabular}{|l|l|l|l|l|}
\hline Natural Image & B & S.D & t & p \\
\hline High & -.014 & .761 & -.144 & .886 \\
\hline Low & .351 & .878 & 2.902 & .006 \\
\hline
\end{tabular}

To test moderating effect in $\mathrm{H} 5$, in model-2, the statistics were $\mathrm{R}^{2}=.548$, Adjusted $\mathrm{R}^{2}=.543, \mathrm{~F}=80.745$, p $>.05$, which was not statistically significant. That is, standardized coefficient of interaction item (Convenience*Cultural image) was $-.011, \mathrm{t}=-238 \mathrm{p}=.812$. Therefore, convenience and cultural image do not have moderating effect [Table 4]. Thus, $\mathrm{H} 5$ was rejected.

Table 4: Interaction effect between convenience advantages and cultural image

\begin{tabular}{|l|l|l|l|l|l|}
\hline \multirow{2}{*}{ Variables } & \multicolumn{2}{|l|}{ Unstandardized Coefficients } & \multirow{2}{*}{} & \multirow{2}{*}{} \\
\cline { 2 - 6 } & B & S.D & $t$ & \\
\hline \multirow{3}{*}{1} & Convenience & .347 & .061 & 6.890 & .000 \\
\cline { 2 - 6 } & Cultural image & .506 & .067 & 6.866 & .000 \\
\hline \multirow{3}{*}{2} & Convenience(Con) & .409 & .267 & 3.450 & .001 \\
\cline { 2 - 6 } & Cultural image(CI) & .559 & .231 & 3.711 & .000 \\
\cline { 2 - 6 } & Con *CI & -.011 & .045 & -.238 & .812 \\
\hline $\mathrm{R}^{2}=.548$ Adjusted $\mathrm{R}^{2}=.541 \mathrm{~F}=80.745$ & & & & \\
\hline
\end{tabular}

The effect of convenience on service satisfaction depending on the level of cultural image (high vs. low). To analyze the relationship, this research divided respondents into two groups (those with high natural image and those with low natural image) and did regression analysis between convenience and visitors' satisfaction for two groups. The analysis showed that for those who have high cultural image, the statistics were $\mathrm{B}=-.203, \mathrm{t}=-2.260, \mathrm{R}^{2}=.381, \mathrm{~F}=22.559, \mathrm{p}>.05$. For those who have low cultural image, the statistics were $\mathrm{B}=.401, \mathrm{t}=2.611 \mathrm{R}^{2}=.618 \mathrm{~F}=15.651, \mathrm{p}<.05$. Therefore, When the Mongolian cultural image was high and low convenience advantages had positive effect on visitors' satisfaction. [Table5].

Table 5: Visitors' satisfaction depending on level of cultural image (high vs. low)

\begin{tabular}{|l|l|l|l|l|}
\hline Cultural Image & B & S.D & t & p \\
\hline High & .203 & .771 & 2.260 & .026 \\
\hline Low & .401 & .792 & 2.611 & .014 \\
\hline
\end{tabular}

\section{Results for $\mathrm{H6}$}

H6 was to test the effect of visitors' satisfaction and revisit intention using regression analysis. The 
analysis showed that in the relationship between two variables, $\mathrm{R}^{2}=.296$ and explanatory power was 29.6 \%. Service satisfaction has positive $(+)$ effect on re-visit intention $(B=.726, p<.05)$. Thus, H6 was supported [Table 6].

Table 6: Visitors' satisfaction and Re-visit intention

\begin{tabular}{|c|l|l|l|l|}
\hline \multirow{2}{*}{ Independent Variable } & \multicolumn{2}{|l|}{ Unstandardized Coefficients } & \multirow{2}{*}{$t$} & \multirow{2}{*}{$p$} \\
\cline { 2 - 4 } & $\mathrm{B}$ & $\mathrm{S} . \mathrm{D}$ & \\
\hline Visitors' satisfaction & .726 & .079 & 9.217 & .000 \\
\hline $\mathrm{R}^{2}=.296, \quad$ Adjusted $\mathrm{R}^{2}=.293, \quad \mathrm{~F}=84.944$ & & \\
\hline
\end{tabular}

\section{Conclusion}

In the tourist industry, the relationships among tourist service quality, service satisfaction and revisit intention are essentially important. This research identified the effect of tourist service quality on visitors' satisfaction, and the effect of visitors' satisfaction on revisit intention. In addition, it tested the moderating effect of levels of natural image and cultural image about Mongolia in the relationship between convenience and service satisfaction. This research found out that the effect of convenience on service satisfaction is moderated differently by the levels of natural image and cultural image (high vs. low). The findings are as follows. First, monetary advantage had positive (+) effect on visitors' satisfaction (H1). Second, safety and security did not have significant effect on visitors' satisfaction (H2). Third, convenience had positive (+) effect on visitors' satisfaction (H3). Forth, when the natural image was high, convenience did not have significant effect on visitors' satisfaction. However, when the natural image was low, convenience had positive effect on service satisfaction (H4). Fifth, there was no interaction effect between convenience and cultural image (H5). Finally, visitors' satisfaction had positive effect on revisit intention (H6). In summary, the more visitors to Mongolia are satisfied with service, the more they are satisfied with the visit. The findings of this research gusset that it is necessary to improve tourism service quality to promote destination service. It is necessary to establish marketing strategies to provide visitors with service suitable to Mongolian image, satisfy tourist needs, and make them willing to revisit Mongolia. As tourists decide to visit a certain destination based on information on the site before visiting the site, and some tourists to Mongolia come to the country to experience nature, it is necessary to establish marketing strategies emphasizing nature or experiencing local life here rather than emphasizing convenience. In contrast, for those who visit Mongolia because they have good cultural image of it, it is efficient to provide them with information on cultural tourism such as museum, hotel, transportation means. While safety of the tourist site is fundamentally important, Mongolian tourists regard that there is no big difference between what they expected about safety of Mongolia and what they actually experienced in the country. Consequently, it is advisable to set the marketing strategy focusing more on monetary benefits and convenience than on safety and security. Through providing them with proper services suitable to the tourism image of Mongolia, it is possible to improve satisfaction of them and make them intend to visit Mongolia again.

\section{Limitation and future research}

Despite such suggestions based on the findings of this research, it has following limitations. First, as the numbers of tourists to Mongolia are very different per season, it was difficult to collect sufficient number of respondents to the survey. From December to May, few people visit Mongolia. Most of respondents to the survey were found to have stayed for only 3-4 days, which is quite a short time to experience beautiful nature of the country. As expected, some people had difficulty in answering the questions. If the survey is conducted in hot season, tourists may have different feelings on nature and adventure. As there can be more elements affecting tourism service, it is necessary to add more elements to tourism service analysis. There may be differences in what they pursue and expect from visit to Mongolia depending on the country they come from. Therefore, it is necessary to consider such aspects in future researches. Moreover, it is necessary to do researches on what those potential visitors to Mongolia expect about tourism service in 
their future visit to Mongolia. H1 on the relationship between Monetary advantages and visitors' satisfaction had $B=.430, p<.05$. The slope was statistically significant.

\section{References}

[1] World Tourism Organization, (2019) Information on www.unwto.org

[2] Mongolian tourism Law, 3.1.3., (2000) Information on www.legalinfo.mn

[3] Statistic information of Mongolia, (2020) Information on www.1212.mn

[4] Mongol bank, (2019) Current situation of the tourism sector and issues to be addressed Information on www.mongolbank.mn

[5] World Economic Forum, (2019) The Travel \& Tourism Competitiveness report. Information on: www.weforum.org

[6] Oliver, R. L. (1980) "A cognitive model of the antecedents and consequences of satisfaction decisions." Journal of marketing research 17(4), 460-469.

[7] Gitlow, Howard S. Planning for quality, productivity, and competitive position. Irwin Professional Pub, 1990.

[8] Pizam, Abraham, Yoram Neumann, and Arie Reichel. "Dimentions of tourist satisfaction with a destination area." Annals of tourism Research 5, no. 3 (1978): 314-322.

[9] Pinkus, Emily, Susan A. Moore, Ross Taplin, and Joanna Pearce. "Re-thinking visitor loyalty at 'once in a lifetime'nature-based tourism destinations: Empirical evidence from Purnululu National Park, Australia." Journal of outdoor recreation and tourism 16 (2016): 7-15.

[10] Dewan, Nargis, and Gwi-Gon Kim. "Foreign Tourist Attitudes and Visit Intentions for Mountaineering Tourism in Pakistan." Journal of Spatial and Organizational Dynamics 8, no. 2 (2020): 173-186.

[11] Jeong, Ji Youn, and John L. Crompton. "The use of odd-ending numbers in the pricing of five tourism services in three different cultures." Tourism Management 62 (2017): 135-146.

[12] Baker, Dwayne A., and John L. Crompton. "Quality, satisfaction and behavioral intentions." Annals of tourism research 27, no. 3 (2000): 785-804.

[13] Amir, Ahmad Fitri, Mohd Noor Ismawi Ismail, and Toh Poh See. "Sustainable tourist environment: Perception of international women travelers on safety and security in Kuala Lumpur." ProcediaSocial and Behavioral Sciences 168 (2015): 123-133.

[14] Um, Seoho, and John L. Crompton. "The roles of perceived inhibitors and facilitators in pleasure travel destination decisions." Journal of travel research 30, no. 3 (1992): 18-25.

[15] George, Richard, and Irma Booyens. "Township tourism demand: Tourists' perceptions of safety and security." In Urban Forum, vol. 25, no. 4, pp. 449-467. Springer Netherlands, 2014.

[16] Shim, Soyeon, and Kenneth C. Gehrt. "Hispanic and Native American adolescents: An exploratory study of their approach to shopping." Journal of Retailing 72, no. 3 (1996): 307-324.

[17] Roy, Sanjit Kumar, Vaibhav Shekhar, Walfried M. Lassar, and Tom Chen. "Customer engagement behaviors: The role of service convenience, fairness and quality." Journal of Retailing and Consumer Services 44 (2018): 293-304.

[18] Beerli, Asuncion, and Josefa D. Martin. "Factors influencing destination image." Annals of tourism research 31, no. 3 (2004): 657-681.

[19] Pike, Steven, and Chris Ryan. "Destination positioning analysis through a comparison of cognitive, affective, and conative perceptions." Journal of travel research 42, no. 4 (2004): 333-342.

[20] Gallarza, Martina G., Irene Gil Saura, and Haydée Calderón García. "Destination image: Towards a conceptual framework." Annals of tourism research 29, no. 1 (2002): 56-78.

[21] Boo, Elizabeth. Ecotourism: the potentials and pitfalls: country case studies. WWF, 1990.

[22] Stylianou-Lambert, Theopisti. "Gazing from home: Cultural tourism and art museums." Annals of Tourism Research 38, no. 2 (2011): 403-421.

[23] Sofield, Trevor HB, and Fung Mei Sarah Li. "Tourism development and cultural policies in China." Annals of tourism research 25, no. 2 (1998): 362-392.

[24] Chen, Ching-Fu, and DungChun Tsai. "How destination image and evaluative factors affect behavioral intentions?." Tourism management 28, no. 4 (2007): 1115-1122.

[25] Loi, Lawrence Teng Iat, Amy Siu Ian So, Iris Sheungting Lo, and Lawrence Hoc Nang Fong. "Does the quality of tourist shuttles influence revisit intention through destination image and satisfaction? The case of Macao." Journal of Hospitality and Tourism Management 32 (2017): 115-123.

[26] Han, Heesup. "Effects of in-flight ambience and space/function on air travelers' decision to select a low-cost airline." Tourism management 37 (2013): 125-135.

[27] George, Richard. "Tourist's perceptions of safety and security while visiting Cape Town." Tourism Management 24, no. 5 (2003): 575-585. 
[28] Kim, Samuel Seongseop, Choong-Ki Lee, and David B. Klenosky. "The influence of push and pull factors at Korean national parks." Tourism management 24, no. 2 (2003): 169-180.

[29] Malik, Mohammad Imran, and M. Sultan Bhat. "Sustainability of tourism development in Kashmir-Is paradise lost?" Tourism management perspectives 16 (2015): 11-21.

[30] Chen, Ching-Fu, and Sambath Phou. "A closer look at destination: Image, personality, relationship and loyalty." Tourism management 36 (2013): 269-278.

[31] Stojanovic, Igor, Luisa Andreu, and Rafael Curras-Perez. "Effects of the intensity of use of social media on brand equity." European journal of management and business economics (2018).

[32] Tan, Wee-Kheng, and Cheng-En Wu. "An investigation of the relationships among destination familiarity, destination image and future visit intention." Journal of Destination Marketing \& Management 5, no. 3 (2016): 214-226. 